\title{
Retro-trochanteric sciatica-like pain: current concept
}

\author{
Khaled Meknas • Oddmund Johansen • \\ Jüri Kartus
}

Received: 10 April 2011/ Accepted: 31 May 2011/Published online: 16 June 2011

(C) The Author(s) 2011. This article is published with open access at Springerlink.com

\begin{abstract}
The aim of this manuscript is to review the current knowledge in terms of retro-trochanteric pain syndrome, make recommendations for diagnosis and differential diagnosis and offer suggestions for treatment options. The terminology in the literature is confusing and these symptoms can be referred to as 'greater trochanteric pain syndrome', 'trochanteric bursitis' and 'trochanteritis', among other denominations. The authors focus on a special type of sciatica, i.e. retro-trochanteric pain radiating down to the lower extremity. The impact of different radiographic assessments is discussed. The authors recommend excluding pathology in the spine and pelvic area before following their suggested treatment algorithm for sciaticalike retro-trochanteric pain. Level of evidence II.
\end{abstract}

Keywords Piriformis - Obturatorius internus .

Trochanteric pain

\section{Introduction}

Pain localised to the hip region may be part of a symptom pattern pointing towards several well-known diseases $[2$,

K. Meknas $(\bowtie) \cdot$ O. Johansen

Department of Orthopaedics, University Hospital of North

Norway, 9038 Troms $\varnothing$, Norway

e-mail: khaled.meknas@unn.no

K. Meknas · O. Johansen

Institute of Clinical Medicine, Faculty of Medicine,

University of Troms $\emptyset$, Troms $\emptyset$, Norway

J. Kartus

Department of Orthopaedics, NU-Hospital Organization,

Trollhättan, Uddevalla, Sweden
37, 39, 60, 70, 95]. Clinical history, findings and supplementary examinations, such as standard radiographs and MRI, might point towards treatable pathology in the back, hip and even the knee. In some patients, the pain may have serious consequences; however, it may be diffuse and have a pattern that is not readily understood and treatment attempts may not be successful. The aetiology of retrotrochanteric pain is multifactorial and the clinical diagnosis can be difficult to determine, as there are several possible differential diagnoses, including intra-articular pathology, extra-articular pathology and referred symptoms from the lumbar spine and pelvis. 'Greater trochanteric pain syndrome' (GTPS) is a common denomination of these kinds of symptom in the literature and it is estimated that it affects between 10 and $25 \%$ of the population in industrialised societies $[15,48,83]$. In primary care settings, the incidence of GTPS is reported to be around 1.8 patients per 1,000 per year [48].

Tortolani et al. [89] found GTPS in $62.7 \%$ of 247 patients who had been evaluated by a spine surgeon for radicular symptoms.

In a prospective, observational study involving 100 consecutive patients with rheumatoid arthritis, Raman and Haslock [73] found that $15 \%$ of the patients had concomitant GTPS. The increased incidence of GTPS in women and patients with leg length discrepancies, low back pain (LBP) and knee pain suggests that changes in lower-limb biomechanics and abnormal force vectors across the hip may be predisposing factors.

In the literature, it has been reported that the prevalence of GTPS in patients with hip pain in the absence of knee or generalised pain is approximately $24 \%$ in women and $9 \%$ in men [83]. This indicates that GTPS is common and greater clinical awareness may identify patients for primary prevention and therapy [83]. However, the overall 
incidence of true retro-trochanteric pain is unknown, as it is often an exclusion diagnosis. Buttock pain and tenderness extending from the sacrum to the greater trochanter, together with pain radiating to the lower extremity, have been described and the sciatic nerve has been suspected of being irritated [7, 20, 53, 62, 82]. In some of these patients, no clear clinical or radiographic pathology in the spine, hip or knee can be found. It has also been claimed that soft tissue pathology in the hip region may cause diffuse, sometimes radiating pain $[4,5,7]$.

This kind of retro-trochanteric pain with radiation has been described as the 'piriformis syndrome' [4, 5, 29]. It may be associated with trauma to the pelvis or buttock [7], anatomical abnormalities like a bipartite piriformis muscle $[14,40]$, the piriformis muscle lying anterior to the nerve [82], or a hypertrophic muscle irritating the sciatic nerve [62, 82] (Figs. 1, 2, 3, 4). Several other diagnoses must be considered for patients with retro-trochanteric pain; they include herniated discs, degenerative changes in the lumbosacral spine, spinal stenosis, osteoarthritis (OA) and minor intra-articular pathology in the hip joint, such as labral tears, and femuro-acetabular impingement (FAI). Furthermore, gynaecological conditions, especially when the right side is affected, should be borne in mind [100].

GTPS, or retro-trochanteric pain, as we would like to call it, frequently radiates with paraesthesia and may often lead to a referral for magnetic resonance imaging (MRI) to consider disc herniation or other pathology, instead of conducting a structured physical examination of the affected soft tissue in the gluteal and hip region.
The aim of the study is to describe conditions which can present as retro-trochanteric pain and to make suggestions for investigation and treatment options.

\section{Differential diagnosis}

Disc herniation

LBP is very common and the number of cases with additional sciatic pain is low in comparison. The compression of a nerve root is one of the most common causes of sciatica; a herniated disc compresses the root in $90 \%$ of cases [39]. Other possible causes of sciatica include lumbar spinal stenosis and, more rarely, tumours or cysts. Typical dermatomal distribution of pain which worsens on coughing, sneezing or straining, increased finger-floor distance and sensory symptoms, such as numbness or paraesthesia, are significant predictors of nerve root compression in patients with low back pain radiating distally into the leg [95].

Medical history and physical examination are the mainstays of sciatica diagnosis. The straight leg raising test or Lasegue's test is commonly used in patients with suspected sciatica. In addition, changes in the Achilles and patellar tendon reflexes and reduced strength in the big toe, ankle and knee are typical signs in patients with nerve root compression. The distribution of pain radiating in the lower limb, a characteristic and definitive feature of the condition, can sometimes be evaluated using pain drawings [39].
Fig. 1 The normal anatomy of the sciatic nerve in relationship to the piriformis muscle. Copyright Catarina Kartus

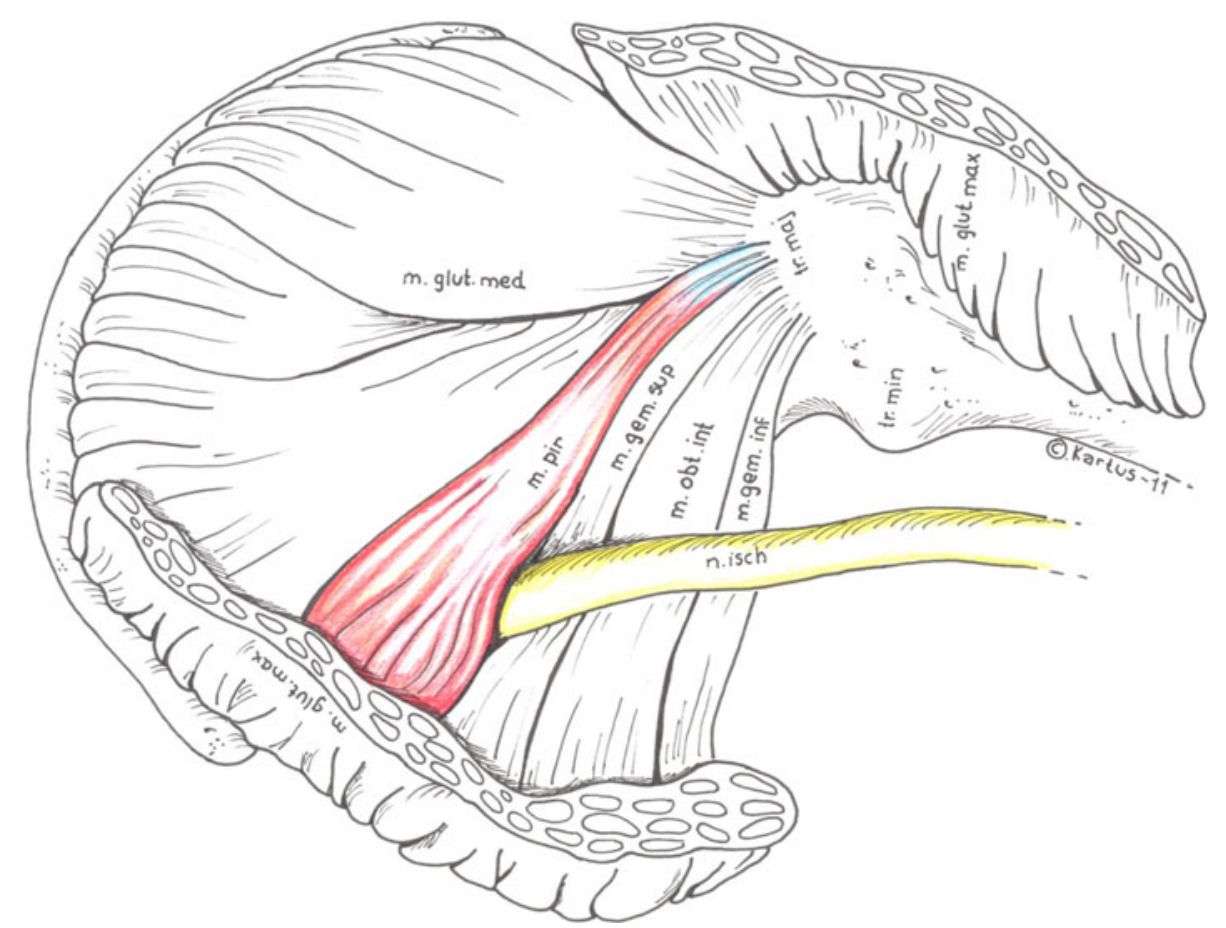


Fig. 2 The bipartite piriformis muscle. Copyright Catarina Kartus

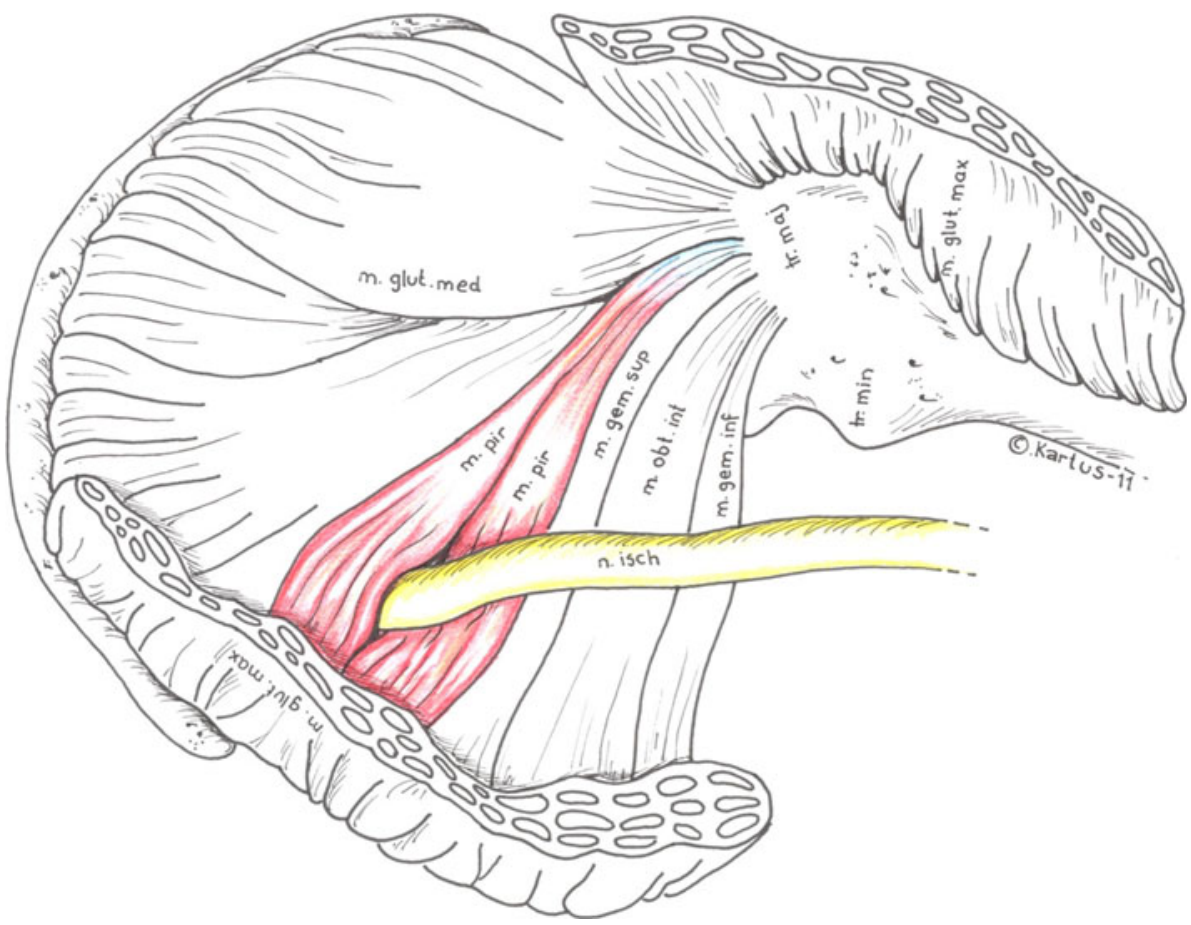

Fig. 3 The piriformis muscle lying anterior to the sciatic nerve. Copyright Catarina Kartus

Disc herniation is reported in $20-36 \%$ of individuals without symptoms of sciatica or low back pain and, furthermore, many patients with clinical symptoms of sciatica do not display lumbar disc herniation on imaging [39]. Conservative treatment strategies for disc herniation are primarily aimed at pain reduction, either by using analgesics or by the non-surgical reduction of pressure on the nerve root using traction, spinal manipulation or

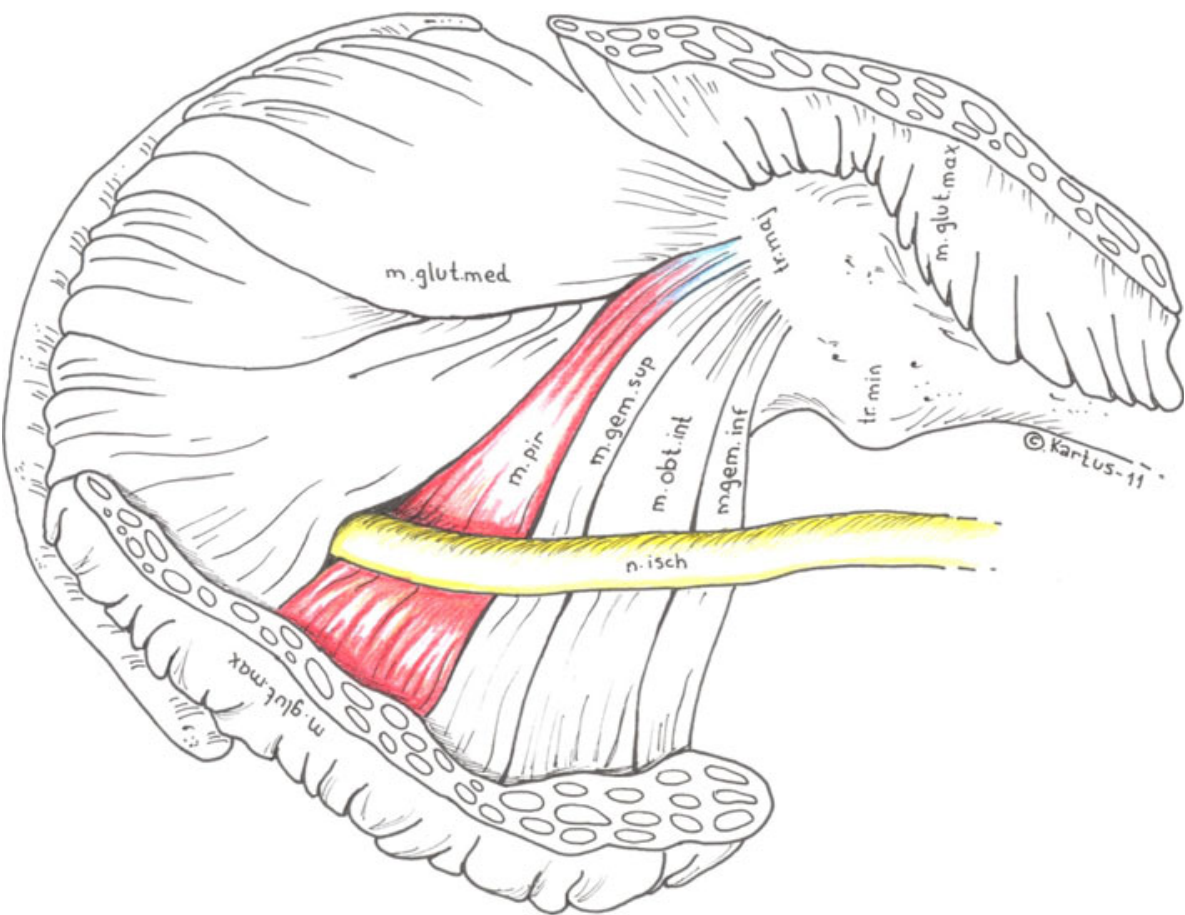

physiotherapy, for example. Conservative treatment regimens are currently the first-line option for patients with sciatica. The adequate management of pain and an active approach, with patients being reassured and advised to continue their daily activities as much as possible, is the preferred treatment strategy [92].

If the patient has not improved after 6-8 weeks of treatment, imaging should be considered to determine 
Fig. 4 The sciatic nerve splits and encircles the piriformis muscle. Copyright Catarina Kartus

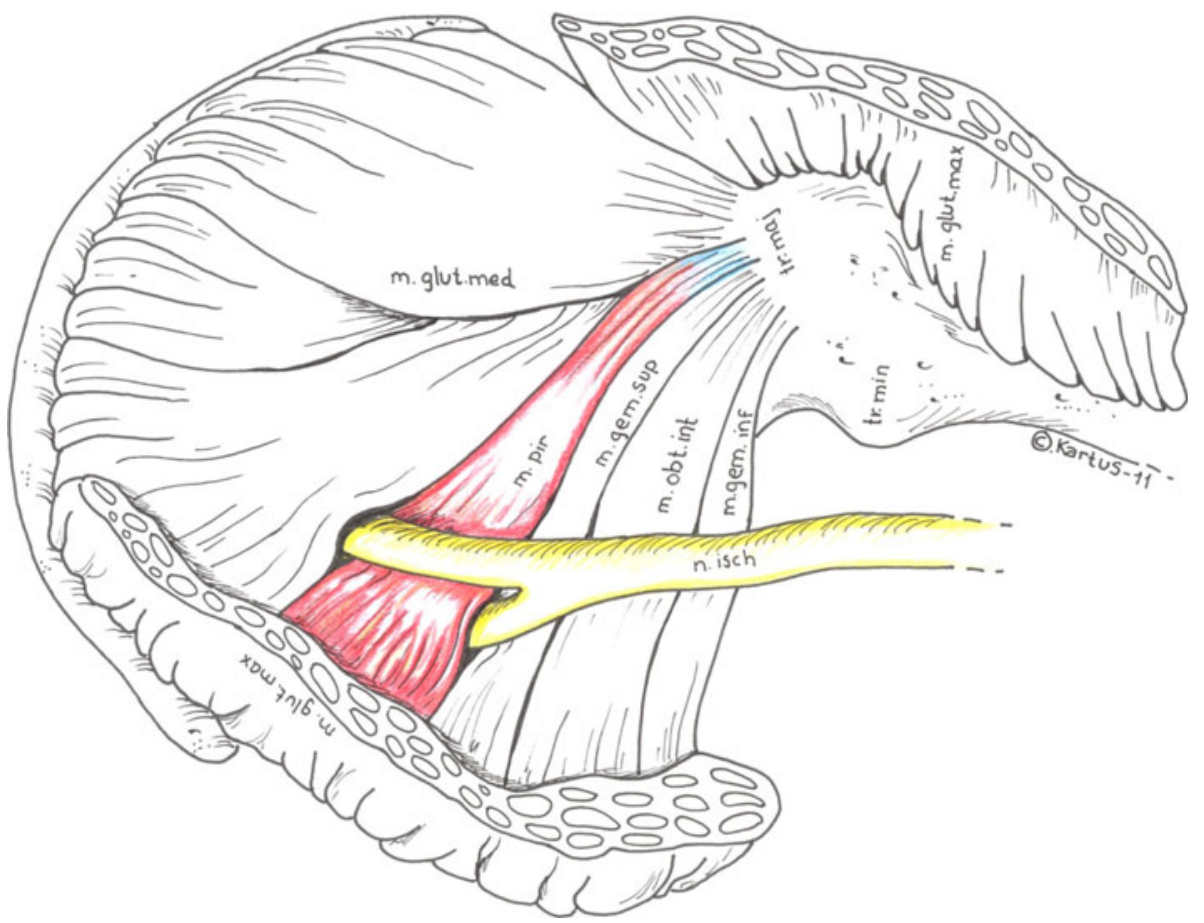

whether a herniated disc with nerve root compression is present. Surgery may be needed to relieve the pressure on the nerve root. There are several surgical methods for treating disc herniation; they include discectomy, microdiscectomy, microendoscopic discectomy, transforaminal endoscopic discectomy and chemonucleolysis. The cauda equine syndrome is an absolute indication for immediate surgery, but elective surgery is the treatment of choice for unilateral sciatica [39].

Niu et al. [66] suggested that several patients had persistent sciatica, despite lumbar decompression surgery for lumbar disc herniation or stenosis, and the 'piriformis syndrome' was subsequently confirmed through a positive response to the injection of a local anaesthetic agent and pain and weakness on forced passive internal rotation of the extended hip (the Freiberg's sign). Eleven of 12 patients in their study were thus successfully treated for the 'piriformis syndrome' with injections and conservative treatment. The overall satisfaction rate was $83 \%$ and they therefore suggested excluding the 'piriformis syndrome' before diagnosing lumbar radiculopathy.

\section{Lumbar spinal stenosis}

Lumbar spinal stenosis is defined as a narrowing of the spinal canal. In some patients, this condition becomes symptomatic. The classic presentation is that of bilateral neurogenic claudication, defined as intermittent pain radiating at varying degrees to the buttocks, thigh and leg, which gets worse with prolonged standing, walking or lumbar extension [70].
However, many individuals remain asymptomatic and radiographic findings do not necessarily correlate with clinical symptoms. Lumbar spinal stenosis occurs with normal vertebral alignment, while some patients also suffer from concomitant degenerative 'spondylolisthesis', which is defined as the forward slipping of one lumbar vertebra in relation to another with an intact neural arch. In most cases, 'spondylolisthesis' affects the L4-L5 level. It commonly occurs in patients over the age of 50 and affects females six times more frequently than males. Degenerative spondylolisthesis is generally asymptomatic, but it can be associated with symptomatic lumbar spinal stenosis and radiculopathy [70].

Treatment options are either non-surgical methods or surgical intervention, depending on the severity of the stenosis and the number of levels involved. Surgical fusion and laminectomy are the methods most commonly used to treat spinal stenosis [70].

The management of degenerative lumbar disease is demanding. Non-surgical treatment consisting of oral pain medication, epidural corticosteroid injections, traction and spinal manipulation has been described with varying results. Surgery may be necessary when the patient has symptoms due to either instability or neurological compression [92].

\section{Osteoarthritis}

Osteoarthritis (OA) is the most common form of arthritis and a leading cause of chronic disability. OA characterised by joint pain, tenderness, limitation of movement and a 
varying degree of inflammation is most common in the hip, knee and hand joints.

Synovitis is an intrinsic component of OA, which becomes more extensive as the disease progresses. It may not be apparent clinically, but it can be detected by arthroscopy, MRI and ultrasound. Synovitis may contribute to the progression of cartilage degradation [2].

The conservative treatment for hip and knee OA includes physiotherapy with an exercise and muscle strengthening programme, cryotherapy and orthotic management, such as footwear or bracing. Furthermore, pharmacotherapy with NSAIDs and analgesics is extensively used in clinical settings, as are intra-articular injections with corticosteroids.

However, the treatment of choice for advanced hip and knee OA in elderly patients is still arthroplasty [60].

Contralateral knee OA, as well as ipsilateral knee and hip OA, has been shown to be associated with GTPS [83, 97].

\section{Piriformis syndrome}

The piriformis muscle originates from the anterior surface of the sacrum and inserts into the upper part of the greater trochanter, passing out of the pelvis through the greater sciatic notch.

Contracture of the piriformis muscle has been thought to cause the 'piriformis syndrome', with a well-known clinical picture with sciatica-like symptoms [52].

Back in 1928, Yoeman [99] reported that sciatica might be caused by a periarthritis involving the anterior sacroiliac ligament, the piriformis muscle and the adjacent branches of the sciatic nerve. In 1947, Robinson [78] introduced the term 'piriformis syndrome'. The incidence of 'piriformis syndrome' among patients with low back pain has been reported to be 5-36\% [11, 68]. One MRI report of 61 patients has shown a lack of nerve root compression in the lumbar spine in spite of symptoms of sciatica in $16.4 \%$ of the patients and $4.9 \%$ of all 61 patients were found to have the 'piriformis syndrome' [100].

It has been argued that the piriformis muscle may irritate the sciatic nerve due to an anatomical abnormality such as a hypertrophic muscle. The entrapment and irritation of the sciatic nerve in the hip region has largely been thought to be influenced by the piriformis muscle. Anatomical variations, such as a bipartite piriformis muscle [14, 40] and the piriformis muscle lying anterior to the nerve [82], have been described as irritating the sciatic nerve (Figs. 2, 3, 4).

The aetiology of 'piriformis syndrome' is not clearly known, although it has been argued that the pain syndrome may be caused by trauma to the pelvis or buttock
[7, 52], in addition to anatomical abnormalities of the piriformis muscle, as mentioned above [14, 40], or as a recurrent problem after spinal surgery [8]. Adhesions between the piriformis muscle and the sciatic nerve have been reported by Benson et al. [7]. Cox et al. [17] argued that the gemelli-obturator internus muscles and the associated bursa should be regarded as possible sources of retro-trochanterically located sciatica-like pain. Overuse of the piriformis muscle, e.g. repetitive trauma or sports injury, was suggested to contribute to the "piriformis syndrome' by Mayrand et al. [52]. The 'piriformis syndrome' has also been reported as a complication following hip replacement surgery [72, 90].

There are no laboratory or radiographic methods for diagnosing the syndrome [4, 34, 42, 69, 79, 93], but there are a few reports in the literature with regard to electrophysiological analysis [22, 35].

A number of methods exist for the treatment of the 'piriformis syndrome' in the hip region. They include physiotherapy $[17,37,52]$, extracorporeal shock wave therapy (ESWT) [23, 41], injections of anaesthetic agents with or without steroids [8, 30, 62, 84] and the surgical release of the tendon $[7,53,85]$. A surgical tenotomy of the piriformis muscle tendon to relieve the nerve from the pressure of the tense muscle has resulted in immediate pain relief [8, 14, 82]. Dezawa et al. [18] even described an arthroscopic technique for the release of the piriformis tendon with promising results.

\section{Obturatorius internus syndrome (OIS)}

The obturator internus muscle is located inferior to the piriformis and arises within the pelvis. It originates at the medial surface of the pubis, covers the obturator foramen and passes through the lesser sciatic notch to insert onto the greater trochanter laterally.

There are 6 external rotator muscles of the hip: the piriformis, superior gemellus, obturator internus, inferior gemellus, obturator externus and quadratus femoris. They are in close anatomical proximity to one another and they work as a functional unit [69].

The tendon of the piriformis muscle was found to have fused with the internal obturator tendon in 48 of 112 cases in an anatomical study [98], which can indicate a strong interaction between the piriformis and internal obturator muscles and the sciatic nerve, and it also runs parallel to the piriformis muscle in its attachment to the trochanter major. Pathology in the internal obturator muscle may be obscured by the complex anatomy in the region. Because of its proximity and similarity in both structure and function, most treatments for the 'piriformis syndrome' also affect the internal obturator [11]. 
Femoro-acetabular impingement (FAI)

Ganz et al. [25] suggested that the morphological abnormalities of the femoro-acetabular joint are possible underlying sources of atraumatic hip problems in athletes. The authors stated that FAI could be caused by structural abnormalities in the proximal femoral neck (CAM), acetabular rim (PINCER) and, more commonly, a combination of these two pathologies. The articular cartilage damage and acetabular labrum tears are caused by these morphological bone abnormalities and FAI is regarded as early hip joint degeneration [24].

Patients with persistent deep groin pain, lateral or buttock pain with a present C-sign (Fig. 5), worsened by prolonged sitting or standing, should be suspected of having FAI.

When the disease is associated with labral tears, patients may report mechanical symptoms, such as catching, locking and clicking $[3,33]$.

In high flexion and internal rotation movements, the abutment and impingement of the labrum and cartilage occurs. Occasionally, a mild injury or specific event may be associated with the onset of pain [81]. On physical examination, reduced ROM is manifest, mainly with passive flexion, internal rotation and the adduction of the affected hip (impingement test) for the CAM-type FAI. With PINCER-type FAI and postero-inferior impingement, hip extension and external rotation may also elicit pain [81].

An initial evaluation of all patients with suspected FAI should include an AP radiograph of the pelvis, in addition to standing AP and lateral views of the affected hip.

Radiographic findings seen in the initial stages of disease may include a prominence in the anterolateral femoral head, the so-called pistol-grip deformity, or the femoral head-and-neck junction [81].

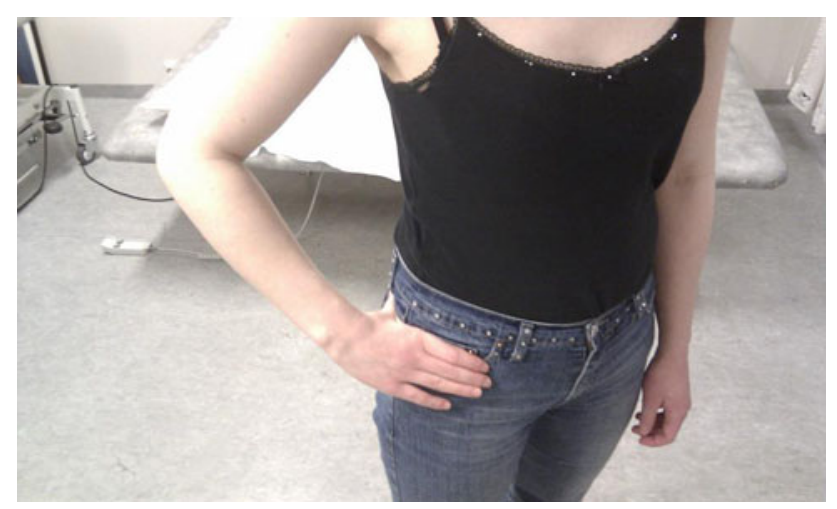

Fig. 5 The patient localises the pain by gripping the affected hip, just above the greater trochanter, between the thumb and index finger, thus forming the $\mathrm{C}$-sign
The treatment options for patients with FAI start with non-surgical treatment. Reducing the level of physical activity and the restriction of specific physical activities, especially those imposing excessive demands on the hip, are encouraged. Non-steroidal anti-inflammatory drugs and physiotherapy are the initial treatment. Physiotherapy can identify activities that aggravate the pain and optimise the alignment and mobility of the hip joint. However, there are few studies that provide solid evidence of the efficacy of the conservative management of FAI. Although conservative treatment may improve symptoms initially, labral and chondral lesions may progress [81].

When the non-surgical treatment fails, surgical treatment may be considered. The goal of surgical treatment is to preserve the hip joint and prevent or delay the need for a total hip replacement. During surgery, FAI is confirmed by direct visualisation and the degree of labral and chondral injuries is observed. A torn labrum is either debrided or repaired, while delaminated cartilage is debrided to a stable edge. Microfracture can be used if subchondral bone is exposed [81].

Murphy et al. [64] reported a low complication rate after the open surgical treatment of FAI, but hip arthroscopy is a minimally invasive procedure and it can be used for both the diagnostic and therapeutic management of FAI. The arthroscopic approach involves less post-operative morbidity and might allow patients to return to highly demanding lifestyles. Philippon et al. [71] reported good results after arthroscopic surgery for the treatment of FAI and 35 of the 45 athletes (78\%) remained active at a professional level an average of 1.6 years after hip arthroscopy.

\section{Other conditions}

Information about gynaecological conditions such as pregnancy, concomitant dysmenorrhoea and cyclicity of sciatica is important. MR imaging of the pelvic region should be obtained because of its usefulness in detecting some gynaecological abnormalities, such as ovarian cysts, fluid in the Douglas pouch and retroversion of the uterus, as well as abnormalities of the piriformis muscle. Of 61 patients, $10(16.4 \%)$ displayed a lack of nerve root compression, as seen in lumbar MR imaging, despite exhibiting sciatica. MR imaging of the pelvic region was performed in 7 patients. Of these, 6 patients showed findings such as hypertrophy of the piriformis, retroversion of the uterus, hysteromyoma, fluid in the Douglas pouch and a cystic lesion in the ovary [100]. It is worth considering that this cohort study is limited; however, pathological conditions in the pelvis and gynaecological diseases must be borne in mind, especially when the right side is affected. Furthermore, it has been suggested that the sigmoid colon plays a 
role in preventing pressure on or stimulation of the sacral plexus on the left side [94].

Other authors have also reported pathological conditions such as ovarian cysts, intra abdominal abscess, ectopic endometriosis and retroversion of the uterus in patients with sciatica [1, 94].

Tendon degeneration and retro-trochanteric pain

Degenerative tendon disorders and overuse injuries in sports and repetitive occupational activities are major problems in the general population, as well as being difficult to treat $[74,96]$. A better understanding of the cellular interaction during tendon injury and degeneration may help to increase the opportunity to treat the condition. The examination of the histological and ultrastructural characteristics of the peri-articular tendons in the hip region could be one way of obtaining a better understanding of the patho-physiological process in this area.

Magra et al. [51] stated that the interaction between the various intrinsic and extrinsic factors and the genetic 'make-up' of an individual may increase the likelihood of one individual developing tendinopathy compared with another. They speculated that gene therapy might prove to be an effective method to aid tendon healing.

The morphological changes in tendinopathy have been analysed in several studies $[6,38,50,59,67]$, including the shoulder [49, 59, 76, 77], elbow [65], patellar and Achilles tendons $[16,46,47,61,75,80]$. However, there is limited information in the literature in terms of the ultrastructural and histological changes in the tendons in the hip and gluteal region. Lempainen et al. [43] confirmed tendinosis using histological analysis in 103 cases of proximal hamstring tendinopathy in athletes. Grimaldi et al. [27] used MRI and showed a significantly smaller piriformis muscle in patients with hip OA compared with patients with nonosteoarthritic hips, while Broadhurst et al. [12] found an abnormal piriformis morphology in a significant number of patients with chronic buttock pain using ultrasonography. Lequesne et al. [45] studied the correlation between MRI findings and clinical and surgical findings in 'refractory greater trochanteric pain syndrome'. They found tears in the gluteus medius and minimus tendons and they introduced the term 'hip rotator cuff syndrome' [44]. Pathology in the short rotators of the hip is regarded as a possible source of retro-trochanterically located sciatica-like pain [17].

In a case report, Mayrand et al. described piriformis syndrome after a football injury and the authors suggested that changes in muscular tension and gait pattern after trauma contributed to overuse of the piriformis muscle, resulting in 'piriformis syndrome' [52].
Some authors have suggested that pain in the osteoarthritic hip joint may be caused by spasm and pressure in the surrounding muscles and tendons (short rotators and psoas muscles) towards the joint capsule, which is richly innervated $[26,28]$.

Howell et al. [31] studied 176 consecutive patients who underwent total hip arthroplasty due to OA and identified a $20 \%$ prevalence of tears in the gluteus medius and minimus. They also confirmed an increasing frequency of abductor mechanism tears with age.

In a recently published study, Meknas et al. [54] performed histological and ultrastructural analysis of tissue samples from the internal obturator tendon. They found that patients with OA of the hip had more scar tissue, more glucos-amino-glycans (GAGs) and more precipitated calcium salts in the degenerative tissue, as seen in the light microscope (Fig. 6), as well as a change in fibril diameter distribution and more non-collagenous and irregular extracellular matrix $(\mathrm{ECM})$, as seen in transmission electron microscopy (TEM), compared with the samples from the internal obturator tendon in patients with a fracture of the collum femoris (FCF) (Figs. 7, 8).

These findings and the lack of distinct inflammatory changes, as seen in the light microscope, therefore indicate that the tendons in the OA group have undergone changes similar to those described in tendons in other locations and referred to as tendinosis. The authors suggested that it is likely that the tendon pathology increases the symptoms already experienced by osteoarthritic patients. There have been no previous reports on whether the tendinous changes around the hip are a normal pathophysiological process in conjunction with the OA disease, or whether the disease actually starts in the tendon and then proceeds to the joint, in a similar manner to what is known as rotator cuff arthropathy in the shoulder.

Domb et al. [19] have suggested that partial tears of the gluteus medius and minimus tendon insertions to the greater trochanter can be misdiagnosed as trochanteric bursitis and this may be a source of chronic debilitating lateral hip pain. The authors presented an endoscopic technique that enables the visualisation, debridement and repair of these tears. Furthermore, they suggested that the diagnosis of gluteus tendinopathy or rupture should initially be made clinically. Clinical examination includes palpation for tenderness, Trendelenburg testing, abduction strength testing and resisted external rotation in the supine position with the hip flexed at $90^{\circ}$.

Theoretically, the pathology in the short rotator muscle tendons could contribute to the symptoms experienced by patients with osteoarthritic hips or degenerative lumbar disease. It is interesting to speculate that, by intervening early in the tendinous disease, it might be possible to reduce the symptoms of OA or even slow the process. 

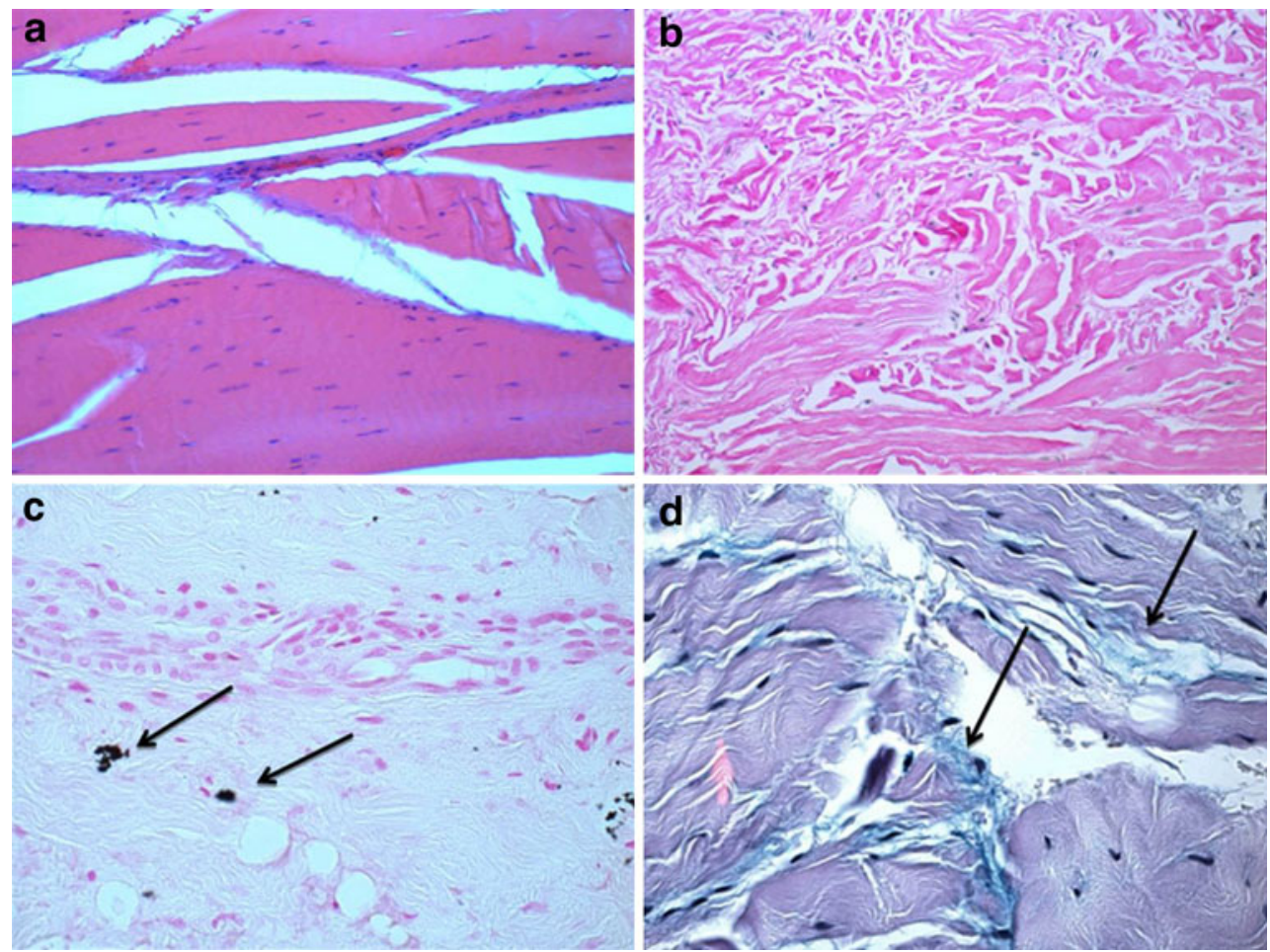

Fig. 6 a Normal tendon from a patient with a fracture of the collum femoris. H\&E staining, original magnification $\times 100$. b Scar tissue from a patient with $\mathrm{OA}$ indicating a ruptured tendon. H\&E staining, original magnification $\times 400$. c Calcium deposits (black stain at arrows) in the scar of a previously ruptured tendon in a patient with

OA. Van Kossa staining, original magnification $\times 400$. d Moderately increased amount of mucin, indicating GAGs between collagen structures, in a patient with OA (blue stain at arrows). Alcian Blue/ Periodic Acid Schiff staining. Original magnification $\times 400$ (republished with the kind permission of John Wiley and Sons)

Fig. 7 a TEM micrograph showing fewer small and medium-sized fibrils in a patient with OA. Original magnification X50,000. b Relative distribution of the fibril diameter size in the internal obturator tendon in a group of patients with OA. c TEM micrograph showing more small and medium-sized fibrils in a patient with a fracture of the collum femoris d Relative distribution of the fibril diameter size in the internal obturator tendon in a group of patients with a fracture of the collum femoris. Original magnification X50,000 (republished with the kind permission of John Wiley and Sons)
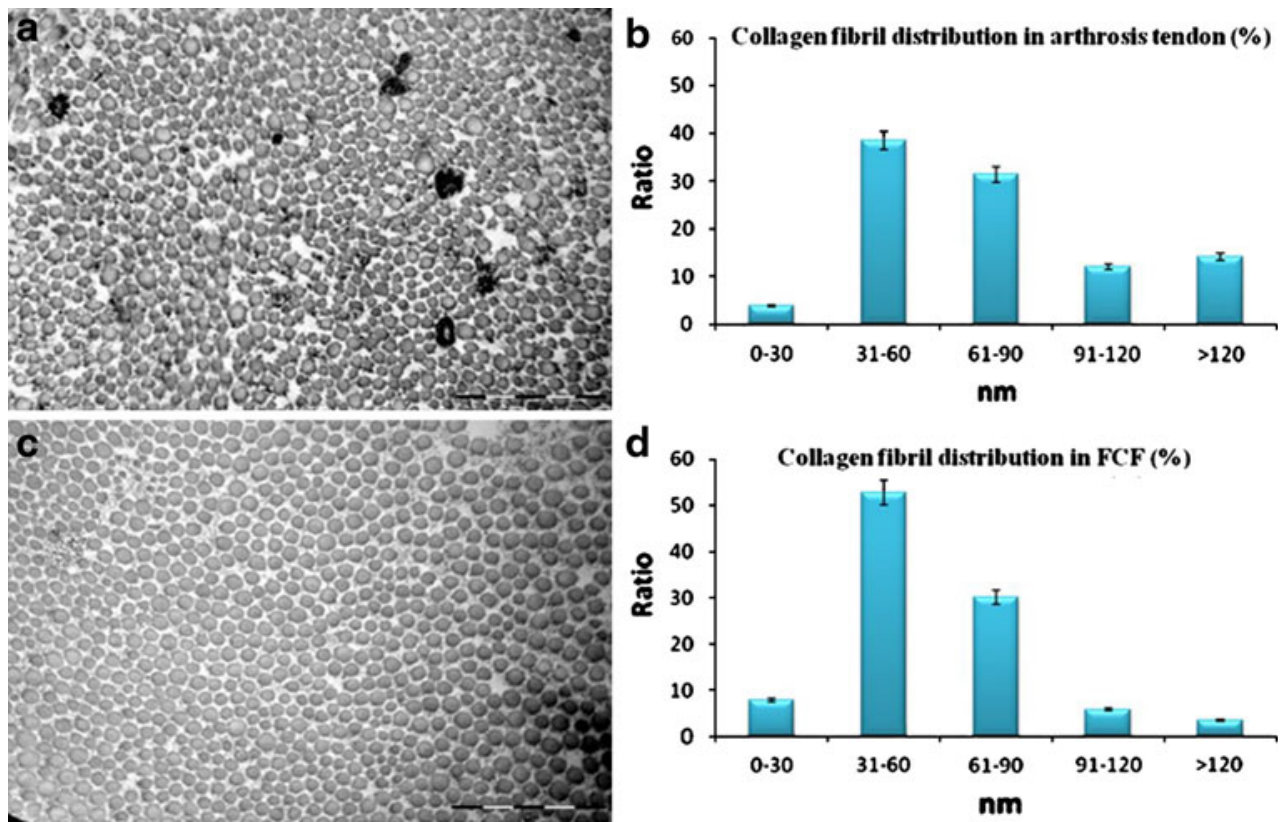

The treatment of tendinosis in patients with mild and moderate OA might therefore be an option in order to reduce the symptoms. Injections of platelet-rich plasma, physiotherapy and also radiofrequency microtenotomy of the small rotator muscle tendons in the hip region are treatment options to consider when it comes to reducing the symptoms in these patients. Favourable results have been reported after using microtenotomy for the treatment of 


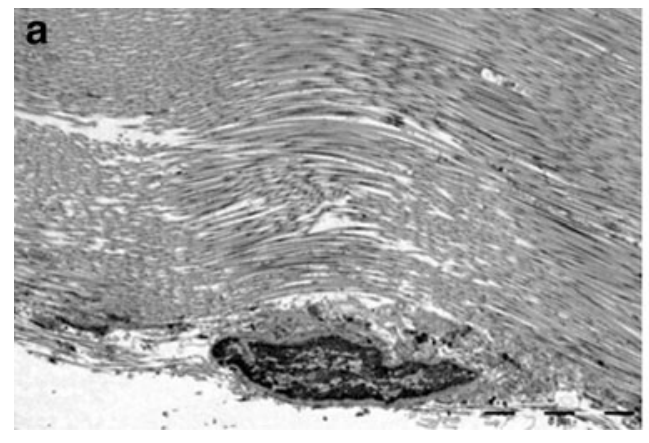

Fig. 8 a TEM micrograph from a patient with a fracture of the collum femoris, showing a homogeneous ECM, where collagen fibrils are running in the same direction. Original magnification $\mathrm{X} 3,000$. b TEM micrograph from a patient with OA, showing collagen fibrils

tendinosis in lateral epicondylitis [57] and patellar [87] and rotator cuff tendinosis [88].

Diagnostic methods

\section{History}

In the clinical history, it is important to consider trauma or other associated conditions which can influence the disease, such as spinal disorders and hip OA. Furthermore, do the patients have pain at rest, during activity or at night? The patients' sitting and walking ability should be evaluated, as well as the presence of limping. Have the patients previously undergone any operations in the spine or pelvic area? Any gynaecological history should also be considered.

\section{Specific symptoms}

- Buttock pain and tenderness in the gluteal region and retro-trochanterically, with the radiation of 'sciaticalike pain', often unilateral but sometimes bilateral

- Loss of or disturbed sensation in the affected extremity

- Limping

- Intolerance of sitting more than 20-30 min [53]

\section{Clinical examination and tests}

- Buttock and leg pain during passive straight leg raising performed by the examiner; the Lasegue's sign

- Pain and weakness on resisted abduction and external rotation of the thigh in a sitting position; the Pace sign

- Pain and weakness on forced passive internal rotation of the extended thigh; the Freiberg sign

- Muscle hypotrophy in the affected extremity (chronic cases)

- Positive Trendelenburg test

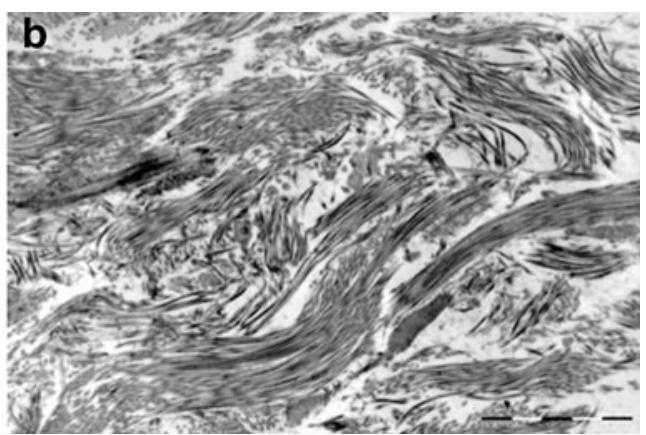

oriented in different directions representing a scar. Furthermore, between the fibrils, empty spaces can be seen, representing noncollagenous ECM. Original magnification X3,000 (republished with the kind permission of John Wiley and Sons)

- Tenderness and pain aggravating with exacerbation of the tight and leg numbness at deep digital palpation in the gluteal and retro-trochanteric area

All these tests are reported to be positive in retro-trochanteric pain syndrome, but they are poorly validated, despite being frequently used in the clinical setting.

An injection of local anaesthetic in the area of the short rotators may be helpful in examining whether the symptoms originate from the spine or from the retro-trochanteric area.

\section{Radiographic assessments}

There are no laboratory or radiographic methods for diagnosing the retro-trochanteric pain syndrome $[4,34,42$, 69, 79, 93]. However, standard antero-posterior radiographs of the pelvis and hips, a lateral view of the hips and either CT or MRI of the lumbar spine are recommended to rule out the possibility that the symptoms experienced by the patients originate from the spine or the hip joint.

When clinical and radiographic examinations raise a suspicion that FAI is present in the hip, an MRI arthrogram is helpful in revealing further intra-articular pathology such as cartilage damage or labral tears. MRI of the pelvis and retro-trochanteric area may also be helpful in recognising pathological conditions in the short rotators of the hip, but there are no reports in the literature in terms of the sensitivity and specificity of an MRI in evaluations of this condition.

The role of MRI is, however, also considered controversial; Blankenbaker et al. [10] studied 256 hips of patients with 'trochanteric pain syndrome' using MRI. They found that $88 \%$ of asymptomatic hips had abnormal findings, with hyperintensity signs in the trochanteric area, and therefore concluded that MRI has high sensitivity to pathology in conjunction with 'trochanteric pain syndrome', while Bird et al. [9] studied 24 patients with GTPS 
and a positive Trendelenburg sign and found approximately $46 \%$ gluteus medius tears and $63 \%$ gluteus medius tendinosis.

Hwang et al. [32] described a 'boomerang'-shaped fluid collection between the obturator internus tendon and the posterior grooved surface of the os ischium seen on MRI images in two case reports. The authors suggested that obturatorius internus bursitis might be considered in patients with hip and buttock pain.

\section{Treatment options}

Once other abnormalities in the spine and the hip joint have been excluded, the treatment options should focus on the soft tissue in the retro-trochanteric area.

Non-surgical approaches for retro-trochanteric pain syndrome

Non-steroidal anti-inflammatory drugs (NSAIDs) and muscle relaxants have been reported to be beneficial in patients with low back pain, including the piriformis syndrome [13, 91]. Fishman et al. [21] reported a good outcome in patients with piriformis syndrome using NSAIDs, muscle relaxants, ice and rest. Injections of anaesthetic agents with or without steroids have been reported with varying results $[8,30,62,84]$, but this kind of disease often tends to be chronic and pharmacological treatment is recommended for a short time period. Physiotherapy is recommended as the first choice of treatment [17, 37, 52].

A number of methods exist for conservative treatment of the 'piriformis syndrome' in the hip region. Extracorporeal shock wave therapy (ESWT) has also been suggested [23, $41]$ and injections of platelet-rich plasma (PRP), as used in other tendinopathies, can be an option $[36,58]$.

Many studies have focused on the relaxation of the piriformis muscle. Even though it is an external rotator, the piriformis muscle has been found to rotate the femur internally when the hip is in flexion [37]. Meknas et al. [56] did not choose to perform the stretching exercises in external rotation. Assuming that a tense internal obturator muscle caused the problems, a different procedure was chosen. To our knowledge, there has been no description of a change in action for the internal obturator muscle from external to internal rotation when the hip is in flexion [37]. In the above cohort study, Meknas et al. reported most pain during passive internal rotation and this was therefore regarded as an efficient stretching manoeuvre for the obturator muscle [56].

Maximum stretching of the internal obturator muscle was thought to be obtained by passive internal rotation, with simultaneous flexion and adduction of the hip. General stretching of the hip muscles was performed in addition, supported by the observation that most muscles around the hip appear to be tense in patients with retrotrochanteric pain syndrome. Specific attention was, however, paid to the small rotators, because their proximity to the sciatic nerve could theoretically cause problems with sciatica-like pain.

Direct massage by a physiotherapist of the tendons of the small external rotators at their insertion at the trochanter was also a part of the treatment programme. Anatomically, the internal obturator muscle is deep to both the piriformis muscle and the sciatic nerve and it runs parallel to the piriformis in its attachment to the trochanter major. Because of its proximity, similar pathway and function, most conservative treatments for patients with 'piriformis syndrome' would affect the internal obturator muscle as well [11]. Guvencer et al. [29] suggested that the internal obturator, gemelli and quadratus femoris tendons share common insertions with the piriformis tendon and can thereby compensate for the loss of its function. The fusion of the piriformis tendon with the obturator internus tendon has previously been confirmed [98]. In the study by Meknas et al. [56], clinical improvement was seen only after the specific treatment programme. It has been suggested that retro-trochanteric pain caused by the piriformis or internal obturator syndrome is often under-diagnosed or overlooked in the clinical setting, because the symptoms may be similar to lumbar spine disorders, such as disc herniations or spinal stenosis $[11,100]$.

\section{Surgical treatment}

Surgical release with tenotomy of the piriformis tendon to relieve the nerve from the pressure of the tense muscle has resulted in immediate pain relief, as reported by several authors [8, 14, 82]. Dezawa et al. [18] even described an arthroscopic technique for the release of the piriformis tendon. An arthroscopic technique for the repair of tears to the gluteus medius has been described by Domb et al. [19]. Moreover, in a review article, Strauss et al. [86] reported an arthroscopic technique for gluteus medius repair using a mechanical shaver to debride the tendon edges, a motorised burr to decorticate and prepare the greater trochanter and a suture anchor to adapt the tendon to the decorticated area.

Meknas et al. [53] performed surgical treatment on patients with an expected 'piriformis syndrome'. During the surgical procedure, no pathology was found around the piriformis muscle and tendon. Exploration, however, revealed clear pathology in all cases, consisting of a very tense internal obturator tendon, which had an impact on the sciatic nerve. Meknas et al. [55] also described favourable long-term improvement after surgical tenotomy of the obturatorius internus in the same group of patients (Figs. 9, 10). In line with Meknas et al., Murata et al. [63] reported an immediate improvement in a patient with a 21-month 
Fig. 9 The sciatic nerve and the internal obturator tendon as found during an operation for retro-trochanteric pain syndrome. The internal obturator tendon is tense and hypertrophic, lying in close contact with the sciatic nerve, which turns sharply over the tendon [53]. Copyright Catarina Kartus
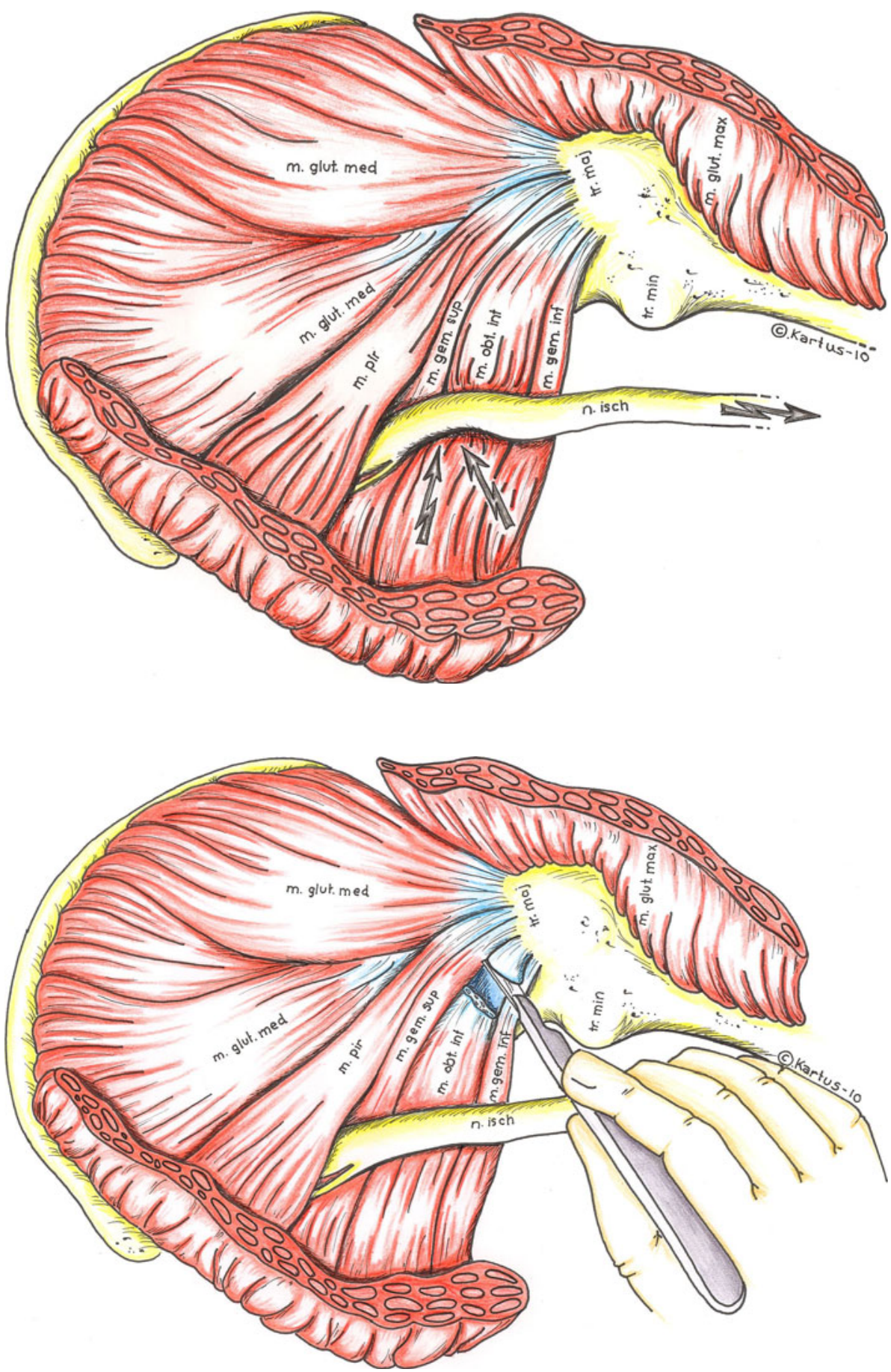

Fig. 10 After sectioning the internal obturator tendon, the sciatic nerve is released from the tendon. Copyright Catarina Kartus history of sciatic pain and numbness, after sectioning the obturator internus muscle, which was found to be stretched and clearly compressing the sciatic nerve. In the same patient, however, the piriformis muscle did not compress the sciatic nerve. The authors concluded that the obturator internus muscle should be considered as a possible cause of sciatic pain and the diagnosis of the obturator internus syndrome can only be made by ruling out other possible causes of sciatic pain, which is similar to the manner in which the piriformis syndrome is diagnosed [63].

\section{Surgical procedure}

The patient is positioned in the lateral decubitus position under general anaesthesia. To reduce bleeding, an injection of $10 \mathrm{ml}$ of $1 \%$ xylocaine and $5 \mu \mathrm{g} / \mathrm{ml}$ adrenalin is made 
from the subcutaneous area down to the piriformis fossa using a spinal needle. The hip is in $30^{\circ}-60^{\circ}$ of flexion, the knee is in slight flexion and a pillow is placed between the knees to achieve abduction of the hip of approximately $15^{\circ}$.

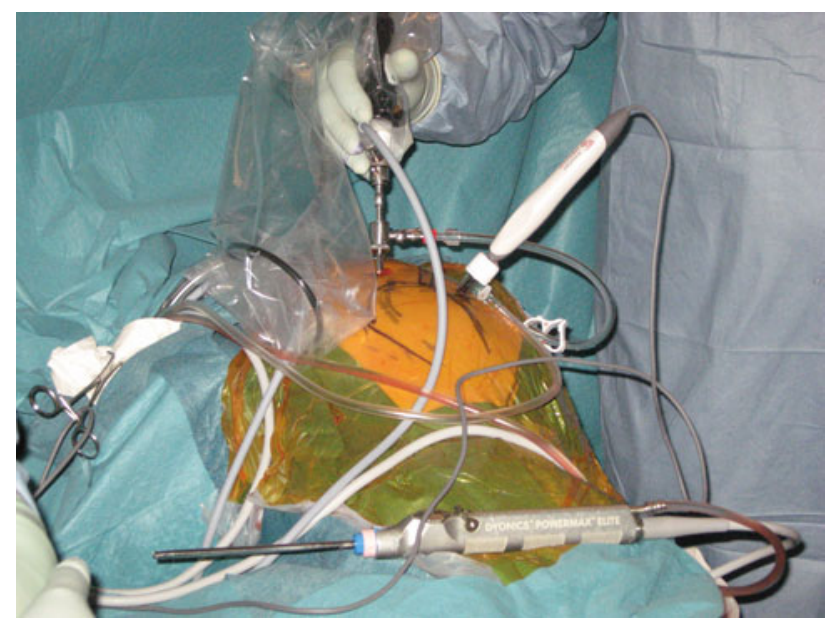

Fig. 11 The lateral portal is located $1-2 \mathrm{~cm}$ distal to the anterior superior iliac spine, in line with the tip of the greater trochanter. The posterolateral portal is located $3-5 \mathrm{~cm}$ proximal to the posterior tip of the greater trochanter, in line with the posterior edge of the trochanter, directed towards the piriformis fossa. Copyright Khaled Meknas

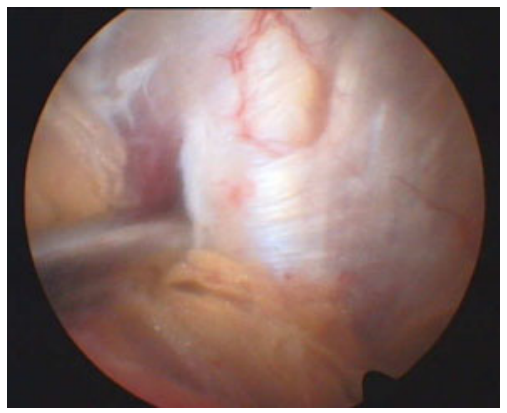

Fig. 12 The gemellus-internal obturator complex is identified and shows hyperaemia in this case. Copyright Khaled Meknas

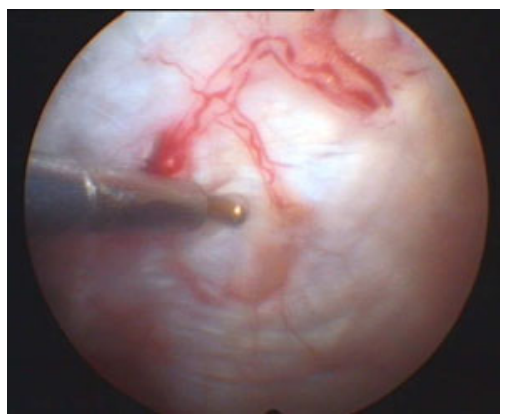

Fig. 13 In this case, the microtenotomy is performed using an electronic microdebrider. Copyright Khaled Meknas
The lateral portal is established $1-2 \mathrm{~cm}$ distal to the anterior-superior iliac spine and in line with the anterior tip of the greater trochanter to access the peri-trochanteric space (Fig. 11). The arthroscope is introduced and directed distally and posteriorly. The initial view should visualise the insertion of the gluteus maximus to the posterior border of the iliotibial band. The posterolateral portal is located $3-5 \mathrm{~cm}$ proximal to the posterior tip of the greater trochanter directed towards the piriformis fossa (Fig. 11). A shaver is then introduced through the posterolateral portal. A trochanteric bursectomy is performed, while paying attention to keep the shaver blade directed away from the gluteus medius. When the piriformis tendon is identified, it should be possible to identify the tendons of the gemellus and obturatorius internus muscles (Fig. 12). The sciatic nerve should now also be possible to visualise and care must be taken to avoid nerve damage caused by the motorised instrument or excessive traction. An electrode is inserted through the posterolateral portal and a

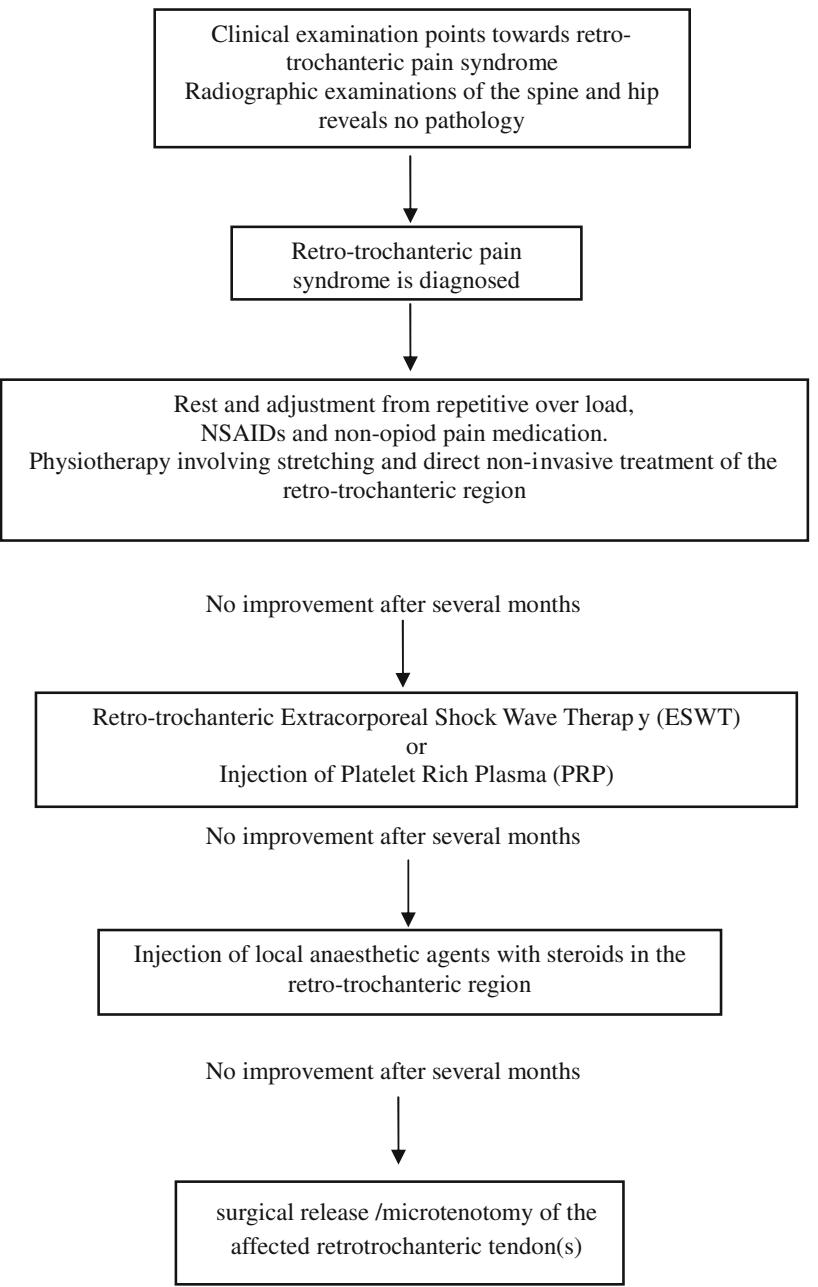

Fig. 14 The treatment algorithm for retro-trochanteric pain syndrome 
microtenotomy of the short rotator affecting the sciatic nerve is performed (Fig. 13).

The postoperative management consists of partial weight-bearing using crutches for 2 weeks and unrestricted range of motion exercises. The above surgical approach has shown promising short-term results (unpublished data by Meknas et al.).

\section{Conclusions}

- A specific stretching programme aimed at relaxing the internal obturator muscle and other muscles around the hip can reduce the symptoms in patients with retrotrochanteric pain and should be the first choice of treatment.

- A tense, irritated obturatorius internus muscle tendon should be considered as a possible source of sciatic nerve impingement with radiating pain and should be considered as a differential diagnosis for sciatica if the patient reveals normal radiographic and clinical examination results directed towards the spine and hip joint.

- Surgical release of the internal obturator muscle can result in both a short- and long-term reduction in pain in patients with retro-trochanteric pain syndrome and should be considered if conservative treatment fails.

- The impact of tendon degeneration and tendinopathy in retro-trochanteric pain syndrome, as well as its impact in the development of OA, appears to be a central question which requires further research.

- A treatment algorithm for retro-trochanteric pain syndrome is presented in Fig. 14.

Acknowlegments The authors thank Catarina Cartus for the professional illustration.

Open Access This article is distributed under the terms of the Creative Commons Attribution Noncommercial License which permits any noncommercial use, distribution, and reproduction in any medium, provided the original author(s) and source are credited.

\section{References}

1. Andrews DW, Friedman NB, Heier L, Erickson A, Lavyne MH (1987) Tuboovarian abscess presenting as sciatic pain: case report. Neurosurgery 21:100-103

2. Attur M, Samuels J, Krasnokutsky S, Abramson SB (2010) Targeting the synovial tissue for treating osteoarthritis (OA): where is the evidence? Best Pract Res Clin Rheumatol 24:71-79

3. Bardakos NV, Vasconcelos JC, Villar RN (2008) Early outcome of hip arthroscopy for femoroacetabular impingement: the role of femoral osteoplasty in symptomatic improvement. J Bone Joint Surg Br 90:1570-1575
4. Barton PM (1991) Piriformis syndrome: a rational approach to management. Pain 47:345-352

5. Beauchesne RP, Schutzer SF (1997) Myositis ossificans of the piriformis muscle: an unusual cause of piriformis syndrome. A case report. J Bone Joint Surg Am 79:906-910

6. Benjamin M, Kaiser E, Milz S (2008) Structure-function relationships in tendons: a review. J Anat 212:211-228

7. Benson ER, Schutzer SF (1999) Posttraumatic piriformis syndrome: diagnosis and results of operative treatment. J Bone Joint Surg Am 81:941-949

8. Benzon HT, Katz JA, Benzon HA, Iqbal MS (2003) Piriformis syndrome: anatomic considerations, a new injection technique, and a review of the literature. Anesthesiology 98:1442-1448

9. Bird PA, Oakley SP, Shnier R, Kirkham BW (2001) Prospective evaluation of magnetic resonance imaging and physical examination findings in patients with greater trochanteric pain syndrome. Arthritis Rheum 44:2138-2145

10. Blankenbaker DG, Ullrick SR, Davis KW, De Smet AA, Haaland B, Fine JP (2008) Correlation of MRI findings with clinical findings of trochanteric pain syndrome. Skeletal Radiol 37:903-909

11. Boyajian-O'Neill LA, McClain RL, Coleman MK, Thomas PP (2008) Diagnosis and management of piriformis syndrome: an osteopathic approach. J Am Osteopath Assoc 108:657-664

12. Broadhurst NA, Simmons DN, Bond MJ (2004) Piriformis syndrome: correlation of muscle morphology with symptoms and signs. Arch Phys Med Rehabil 85:2036-2039

13. Browning R, Jackson JL, O'Malley PG (2001) Cyclobenzaprine and back pain: a meta-analysis. Arch Intern Med 161:1613-1620

14. Chen WS (1994) Bipartite piriformis muscle: an unusual cause of sciatic nerve entrapment. Pain 58:269-272

15. Collee G, Dijkmans BA, Vandenbroucke JP, Cats A (1991) Greater trochanteric pain syndrome (trochanteric bursitis) in low back pain. Scand J Rheumatol 20:262-266

16. Cook JL, Feller JA, Bonar SF, Khan KM (2004) Abnormal tenocyte morphology is more prevalent than collagen disruption in asymptomatic athletes' patellar tendons. J Orthop Res 22:334-338

17. Cox JM, Bakkum BW (2005) Possible generators of retrotrochanteric gluteal and thigh pain: the gemelli-obturator internus complex. J Manipulative Physiol Ther 28:534-538

18. Dezawa A, Kusano S, Miki H (2003) Arthroscopic release of the piriformis muscle under local anesthesia for piriformis syndrome. Arthroscopy 19:554-557

19. Domb BG, Nasser RM, Botser IB (2010) Partial-thickness tears of the gluteus medius: rationale and technique for trans-tendinous endoscopic repair. Arthroscopy 26:1697-1705

20. Durrani Z, Winnie AP (1991) Piriformis muscle syndrome: an underdiagnosed cause of sciatica. J Pain Symptom Manage 6:374-379

21. Fishman LM, Schaefer MP (2003) The piriformis syndrome is underdiagnosed. Muscle Nerve 28:646-649

22. Fishman LM, Zybert PA (1992) Electrophysiologic evidence of piriformis syndrome. Arch Phys Med Rehabil 73:359-364

23. Furia JP, Rompe JD, Maffulli N (2009) Low-energy extracorporeal shock wave therapy as a treatment for greater trochanteric pain syndrome. Am J Sports Med 37:1806-1813

24. Ganz R, Leunig M, Leunig-Ganz K, Harris WH (2008) The etiology of osteoarthritis of the hip: an integrated mechanical concept. Clin Orthop Relat Res 466:264-272

25. Ganz R, Parvizi J, Beck M, Leunig M, Notzli H, Siebenrock KA (2003) Femoroacetabular impingement: a cause for osteoarthritis of the hip. Clin Orthop Relat Res 417:112-120

26. Goddard NJ, Gosling PT (1988) Intra-articular fluid pressure and pain in osteoarthritis of the hip. J Bone Joint Surg Br 70:52-55 
27. Grimaldi A, Richardson C, Stanton W, Durbridge G, Donnelly W, Hides J (2009) The association between degenerative hip joint pathology and size of the gluteus medius, gluteus minimus and piriformis muscles. Man Ther 14:605-610

28. Gronblad M, Korkala O, Liesi P, Karaharju E (1985) Innervation of synovial membrane and meniscus. Acta Orthop Scand $56: 484-486$

29. Guvencer M, Akyer P, Iyem C, Tetik S, Naderi S (2008) Anatomic considerations and the relationship between the piriformis muscle and the sciatic nerve. Surg Radiol Anat 30:467-474

30. Hanania M (1997) New technique for piriformis muscle injection using a nerve stimulator. Reg Anesth 22:200-202

31. Howell GE, Biggs RE, Bourne RB (2001) Prevalence of abductor mechanism tears of the hips in patients with osteoarthritis. J Arthroplasty 16:121-123

32. Hwang JY, Lee SW, Kim JO (2008) MR imaging features of obturator internus bursa of the hip. Korean J Radiol 9:375-378

33. Jaberi FM, Parvizi J (2007) Hip pain in young adults: femoroacetabular impingement. J Arthroplasty 22:37-42

34. Jankiewicz JJ, Hennrikus WL, Houkom JA (1991) The appearance of the piriformis muscle syndrome in computed tomography and magnetic resonance imaging. A case report and review of the literature. Clin Orthop Relat Res 262:205-209

35. Jawish RM, Assoum HA, Khamis CF (2010) Anatomical, clinical and electrical observations in piriformis syndrome. J Orthop Surg Res 5:3. doi:10.1186/1749-799X-5-3

36. Kajikawa Y, Morihara T, Sakamoto H, Matsuda K, Oshima Y, Yoshida A et al (2008) Platelet-rich plasma enhances the initial mobilization of circulation-derived cells for tendon healing. J Cell Physiol 215:837-845

37. Keskula DR, Tamburello M (1992) Conservative management of Piriformis syndrome. J Athl Train 27:102-110

38. Kjaer M (2004) Role of extracellular matrix in adaptation of tendon and skeletal muscle to mechanical loading. Physiol Rev 84:649-698

39. Koes BW, van Tulder MW, Peul WC (2007) Diagnosis and treatment of sciatica. BMJ 334:1313-1317

40. Kosukegawa I, Yoshimoto M, Isogai S, Nonaka S, Yamashita T (2006) Piriformis syndrome resulting from a rare anatomic variation. Spine (Phila Pa 1976) 31:E664-E666

41. Krasny C, Enenkel M, Aigner N, Wlk M, Landsiedl F (2005) Ultrasound-guided needling combined with shock-wave therapy for the treatment of calcifying tendonitis of the shoulder. J Bone Joint Surg Br 87:501-507

42. Lee EY, Margherita AJ, Gierada DS, Narra VR (2004) MRI of piriformis syndrome. AJR Am J Roentgenol 183:63-64

43. Lempainen L, Sarimo J, Mattila K, Vaittinen S, Orava S (2009) Proximal hamstring tendinopathy: results of surgical management and histopathologic findings. Am J Sports Med 37:727-734

44. Lequesne M (2006) From "periarthritis" to hip "rotator cuff" tears. Trochanteric tendinobursitis. Joint Bone Spine 73:344-348

45. Lequesne M, Djian P, Vuillemin V, Mathieu P (2008) Prospective study of refractory greater trochanter pain syndrome. MRI findings of gluteal tendon tears seen at surgery. Clinical and MRI results of tendon repair. Joint Bone Spine 75:458-464

46. Lian O, Scott A, Engebretsen L, Bahr R, Duronio V, Khan K (2007) Excessive apoptosis in patellar tendinopathy in athletes. Am J Sports Med 35:605-611

47. Liden M, Movin T, Ejerhed L, Papadogiannakis N, Blomen E, Hultenby $\mathrm{K}$ et al (2008) A histological and ultrastructural evaluation of the patellar tendon 10 years after reharvesting its central third. Am J Sports Med 36:781-788

48. Lievense A, Bierma-Zeinstra S, Schouten B, Bohnen A, Verhaar J, Koes B (2005) Prognosis of trochanteric pain in primary care. Br J Gen Pract 55:199-204
49. Lovering RM, Russ DW (2008) Fiber type composition of cadaveric human rotator cuff muscles. J Orthop Sports Phys Ther 38:674-680

50. Magnusson SP, Hansen P, Kjaer M (2003) Tendon properties in relation to muscular activity and physical training. Scand J Med Sci Sports 13:211-223

51. Magra M, Maffulli N (2008) Genetic aspects of tendinopathy. J Sci Med Sport 11:243-247

52. Mayrand N, Fortin J, Descarreaux M, Normand MC (2006) Diagnosis and management of posttraumatic piriformis syndrome: a case study. J Manipulative Physiol Ther 29:486-491

53. Meknas K, Christensen A, Johansen O (2003) The internal obturator muscle may cause sciatic pain. Pain 104:375-380

54. Meknas K, Johansen O, Steigen SE, Olsen R, Jorgensen L, Kartus J (2011) Could tendinosis be involved in osteoarthritis? Scand J Med Sci Sports. doi:10.1111/j.1600-0838.2010.01287.x. [Epub ahead of print]

55. Meknas K, Kartus J, Letto JI, Christensen A, Johansen O (2009) Surgical release of the internal obturator tendon for the treatment of retro-trochanteric pain syndrome: a prospective randomized study, with long-term follow-up. Knee Surg Sports Traumatol Arthrosc 17:1249-1256

56. Meknas K, Kartus J, Letto JI, Flaten M, Johansen O (2009) A 5-year prospective study of non-surgical treatment of retro-trochanteric pain. Knee Surg Sports Traumatol Arthrosc 17:996-1002

57. Meknas K, Odden-Miland A, Mercer JB, Castillejo M, Johansen O (2008) Radiofrequency microtenotomy: a promising method for treatment of recalcitrant lateral epicondylitis. Am J Sports Med 36:1960-1965

58. Mishra A, Woodall J Jr, Vieira A (2009) Treatment of tendon and muscle using platelet-rich plasma. Clin Sports Med 28:113-125

59. Molloy TJ, Kemp MW, Wang Y, Murrell GA (2006) Microarray analysis of the tendinopathic rat supraspinatus tendon: glutamate signaling and its potential role in tendon degeneration. J Appl Physiol 101:1702-1709

60. Moskowitz RW, Hochberg MC, Goldberg VM (2007) Osteoarthritis diagnosis and medical/surgical managment. Lippincott $4: 257-258$

61. Movin T, Gad A, Reinholt FP, Rolf C (1997) Tendon pathology in long-standing achillodynia. Biopsy findings in 40 patients. Acta Orthop Scand 68:170-175

62. Mullin V, de Rosayro M (1990) Caudal steroid injection for treatment of piriformis syndrome. Anesth Analg 71:705-707

63. Murata Y, Ogata S, Ikeda Y, Yamagata M (2009) An unusual cause of sciatic pain as a result of the dynamic motion of the obturator internus muscle. Spine J 9(6):e16-e18

64. Murphy S, Tannast M, Kim YJ, Buly R, Millis MB (2004) Debridement of the adult hip for femoroacetabular impingement: indications and preliminary clinical results. Clin Orthop Relat Res 429:178-181

65. Nirschl RP, Ashman ES (2003) Elbow tendinopathy: tennis elbow. Clin Sports Med. 22:813-836

66. Niu CC, Lai PL, Fu TS, Chen LH, Chen WJ (2009) Ruling out piriformis syndrome before diagnosing lumbar radiculopathy. Chang Gung Med J 32(2):182-187

67. Oryan A, Shoushtari AH (2008) Histology and ultrastructure of the developing superficial digital flexor tendon in rabbits. Anat Histol Embryol 37:134-140

68. Pace JB, Nagle D (1976) Piriform syndrome. West J Med 124:435-439

69. Papadopoulos EC, Khan SN (2004) Piriformis syndrome and low back pain: a new classification and review of the literature. Orthop Clin North Am 35:65-71 
70. Park DK, An HS, Lurie JD, Zhao W, Tosteson A, Tosteson TD et al. (2010) Does multilevel lumbar stenosis lead to poorer outcomes?: a subanalysis of the Spine Patient Outcomes Research Trial (SPORT) lumbar stenosis study. Spine (Phila Pa 1976) 35:439-446

71. Philippon M, Schenker M, Briggs K, Kuppersmith D (2007) Femoroacetabular impingement in 45 professional athletes: associated pathologies and return to sport following arthroscopic decompression. Knee Surg Sports Traumatol Arthrosc 15:908-914

72. Pokorny D, Jahoda D, Veigl D, Pinskerova V, Sosna A (2006) Topographic variations of the relationship of the sciatic nerve and the piriformis muscle and its relevance to palsy after total hip arthroplasty. Surg Radiol Anat 28:88-91

73. Raman D, Haslock I (1982) Trochanteric bursitis-a frequent cause of 'hip' pain in rheumatoid arthritis. Ann Rheum Dis 41:602-603

74. Rees JD, Maffulli N, Cook J (2009) Management of tendinopathy. Am J Sports Med 37:1855-1867

75. Richards PJ, Win T, Jones PW (2005) The distribution of microvascular response in Achilles tendinopathy assessed by colour and power Doppler. Skeletal Radiol 34:336-342

76. Riley G (2008) Tendinopathy-from basic science to treatment. Nat Clin Pract Rheumatol 4:82-89

77. Riley GP, Harrall RL, Constant CR, Chard MD, Cawston TE, Hazleman BL (1994) Tendon degeneration and chronic shoulder pain: changes in the collagen composition of the human rotator cuff tendons in rotator cuff tendinitis. Ann Rheum Dis 53:359-366

78. Robinson DR (1947) Piriformis syndrome in relation to sciatica pain. AmJ Surg 3:355-358

79. Rodrigue T, Hardy RW (2001) Diagnosis and treatment of piriformis syndrome. Neurosurg Clin N Am 12:311-319

80. Samiric T, Parkinson J, Ilic MZ, Cook J, Feller JA, Handley CJ (2009) Changes in the composition of the extracellular matrix in patellar tendinopathy. Matrix Biol 28:230-236

81. Samora JB, Ng VY, Ellis TJ (2011) Femoroacetabular impingement: a common cause of hip pain in young adults. Clin J Sport Med 21:51-56

82. Sayson SC, Ducey JP, Maybrey JB, Wesley RL, Vermilion D (1994) Sciatic entrapment neuropathy associated with an anomalous piriformis muscle. Pain 59:149-152

83. Segal NA, Felson DT, Torner JC, Zhu Y, Curtis JR, Niu J et al (2007) Greater trochanteric pain syndrome: epidemiology and associated factors. Arch Phys Med Rehabil 88:988-992

84. Smith J, Hurdle MF, Locketz AJ, Wisniewski SJ (2006) Ultrasound-guided piriformis injection: technique description and verification. Arch Phys Med Rehabil 87:1664-1667
85. Solheim LF, Siewers P, Paus B (1981) The piriformis muscle syndrome. Sciatic nerve entrapment treated with section of the piriformis muscle. Acta Orthop Scand 52:73-75

86. Strauss EJ, Nho SJ, Kelly BT (2010) Greater trochanteric pain syndrome. Sports Med Arthrosc 18:113-119

87. Tasto JP (2006) The role of radiofrequency-based devices in shaping the future of orthopedic surgery. Orthopedics 29:874-875

88. Taverna E, Battistella F, Sansone V, Perfetti C, Tasto JP (2007) Radiofrequency-based plasma microtenotomy compared with arthroscopic subacromial decompression yields equivalent outcomes for rotator cuff tendinosis. Arthroscopy 23:1042-1051

89. Tortolani PJ, Carbone JJ, Quartararo LG (2002) Greater trochanteric pain syndrome in patients referred to orthopedic spine specialists. Spine J 2:251-254

90. Uchio Y, Nishikawa U, Ochi M, Shu N, Takata K (1998) Bilateral piriformis syndrome after total hip arthroplasty. Arch Orthop Trauma Surg 117:177-179

91. van Tulder MW, Scholten RJ, Koes BW, Deyo RA (2000) Nonsteroidal anti-inflammatory drugs for low back pain: a systematic review within the framework of the Cochrane Collaboration Back Review Group. Spine (Phila Pa 1976) 25:2501-2513

92. van TM, Peul W, Koes B (2010) Sciatica: what the rheumatologist needs to know. Nat Rev Rheumatol 6:139-145

93. Vandertop WP, Bosma NJ (1991) The piriformis syndrome. A case report. J Bone Joint Surg Am 73:1095-1097

94. Vercellini P, Chapron C, Fedele L, Frontino G, Zaina B, Crosignani PG (2003) Evidence for asymmetric distribution of sciatic nerve endometriosis. Obstet Gynecol 102:383-387

95. Vroomen PC, de Krom MC, Wilmink JT, Kester AD, Knottnerus JA (2002) Diagnostic value of history and physical examination in patients suspected of lumbosacral nerve root compression. J Neurol Neurosurg Psychiatry 72:630-634

96. Warden SJ (2007) Animal models for the study of tendinopathy. Br J Sports Med 41:232-240

97. Williams BS, Cohen SP (2009) Greater trochanteric pain syndrome: a review of anatomy, diagnosis and treatment. Anesth Analg 108:1662-1670

98. Windisch G, Braun EM, Anderhuber F (2007) Piriformis muscle: clinical anatomy and consideration of the piriformis syndrome. Surg Radiol Anat 29:37-45

99. Yeoman W (1928) The relation of arthritis of the Sacroiliac joint to sciatica. Lancet 2:1119-1122

100. Yoshimoto M, Kawaguchi S, Takebayashi T, Isogai S, Kurata Y, Nonaka S et al (2009) Diagnostic features of sciatica without lumbar nerve root compression. J Spinal Disord Tech $22: 328-333$ 